\title{
A COMBINATION DNA VACCINE ENCODING NUCLEOSIDE HYDROLASE 36 AND GLYCOPROTEINE 63 PROTECTS FEMALE BUT NOT MALE HAMSTERS AGAINST LEISHMANIA MEXICANA
}

\author{
CHALÉ-BALBOA W.G.*, MUT-MARTIN M.**, RAMIREZ-SIERRA M.J.*, GARCIA-MISS M.R.*** \& DUMONTEIL E.****
}

\section{Summary:}

Leishmaniasis is a group of diseases caused by protozoan parasites of the Leishmania genus. Previous studies have shown that a DNA vaccine encoding Leishmania donovani antigen nucleoside hydrolase 36 and L. mexicana glycoprotein 63 is protective in mice. We investigated here the efficacy of this DNA vaccine to induce protection in golden hamsters. Male hamsters were more susceptible to infection by Leishmania mexicana than females. Following immunization with two doses of the DNA vaccine, only females resulted protected while males developed normal lesions.

KEY WORDS : leishmaniasis, vaccine, hamster.
Résumé : UNE COMBINAISON DE VACCINS D'ADN CODANT POUR L'HYDROLASE DE NUCLÉOSIDE 36 ET LA GLYCOPROTÉINE 63 PROTĖGE LES HAMSTERS FEMELLES MAIS PAS LES MÂLES CONTRE LEISHMANIA MEXICANA

La leishmaniose est un groupe de maladies causé par des parasites protozoaires du genre Leishmania. Des études antérieures ont montré qu'un vaccin d'ADN codant pour les antigènes hydrolase de nucleoside 36 de Leishmania donovani et la glycoprotéine 63 de L. mexicana est protecteur chez la souris. Nous avons étudié ici l'efficacité de ce vaccin pour induire une protection chez le hamster. Les hamsters mâles ont montré une plus grande susceptibilité à l'infection que les femelles. Après la vaccination avec deux doses de vaccin d'ADN, seules les hamsters femelles furent protégées, alors que les mâles développèrent des lésions de taille normale.

MOTS CLÉS : leishmaniose, vaccin, hamster.

\footnotetext{
L
} eishmaniasis is a group of diseases caused by protozoan parasites of the Leishmania genus. They phages and cause different forms of disease, depending on the Leishmania species. Because of their major disease burden, intensive efforts have been devoted to vaccine development against this parasite (Dumonteil et al., 2001; Palatnik-de-Sousa, 2008). L. mexicana causes localized cutaneous leishmaniasis, and is one of the most frequent species found in Mexico (Andrade-Narvaez et al., 1990; Garcia-Miss et al., 1990). In some cases, it may also lead to diffuse as well as visceral leishmaniasis (Ramos-Santos et al., 2000; Velasco et al., 1989).

DNA vaccines have been shown to induce a preferentially Th1 immume response, which is necessary for

\footnotetext{
* Laboratorio de Parasitología, Centro de Investigaciones Regionales "Dr. Hideyo Noguchi", Universidad Autónoma de Yucatán, Mérida, Yucatán, México

*: Laboratorio de Inmunología, Centro de Investigaciones Regionales "Dr. Hideyo Noguchi", Universidad Autónoma de Yucatán, Mérida, Yucatán, México.

**** Department of Tropical Medicine, Tulane University, School of Public Health and Tropical Medicine, New Orleans, LA, USA. Correspondence: Eric Dumonteil, Department of Tropical Medicine, School of Public Health and Tropical Medicine, Tulane University, 1440 Canal St., Ste 2228, New Orleans, LA, 70112, USA.

Tel.: (504) 9885321 - Fax: (504) 5877313.

E-mail: edumonte@tulane.edu
}

the elimination of intracellular parasites and are thus a promising strategy to control Leishmania (Dumonteil, 2007). Previously we found that a DNA vaccine encoding $L$. donovani antigen nucleoside hydrolase (NH)36 induced protection against both $L$. chagasi (viceral leishmaniasis) and L. mexicana (cutaneous leishmniasis) in mice (Aguilar-Be et al., 2005). Further studies indicated that a recombinant $\mathrm{NH}$ vaccine was also protective against L. major (Al-Wabel et al., 2007) and that the NH36 DNA vaccine was usefull for the therapy of $L$. chagasi murine infection (Gamboa-León et al., 2006). We further optimized this vaccine by combining it with a plasmid encoding L. mexicana glycopreotein (GP)63 and aluminium phosphate as an adjuvant, which improved its protective efficacy against L. mexicana in BALB/c mice (Rosado-Vallado et al., 2005). While these results in mice are encouraging, it is necessary to further evaluate this DNA vaccine in other animal models. Hamsters are considered a highly susceptible host (Garg and Dube, 2006) for a variety of Leishmania species, including L. major, L. mexicana, L. guyamensis, L. panamensis, L. infantum and L. chagasi (Arruda et al., 2002; Melby et al., 2001; Oliveira and Cecchini, 2000; Requena et al., 2000; Soliman, 2006; Travi et al., 2002). We thus investigated here the efficacy of a DNA vaccine encoding NH36 and GP63 to induce protection in male and female golden hamster. 


\section{MATERIALS AND METHODS}

\section{IMMUNIZATION}

$\mathrm{P}$ lasmid DNA vaccines encoding L. donovani $\mathrm{NH} 36$ and L. mexicana GP63 were purified from a fresh culture of transformed DH5a Escherichia coli bacteria as described before (Rosado-Vallado et al., 2005). Purity and quality of the plasmids was assessed by agarose gel electrophoresis, restriction digestion profiles and spectroscopic analysis. Groups of 6-12 syrian golden hamsters (Mesocricetus auratus) were immunized via intramuscular with two doses of $100 \mu \mathrm{g}$ of DNA encoding NH36 and GP63 antigens and $45 \mu \mathrm{g}$ of $\mathrm{AlPO}_{4}$ as adjuvant two weeks apart, as used before in mice (Rosado-Vallado et al., 2005). Control groups received saline solution or an identical dose of the empty plasmid vector with adjuvant. The protocol was approved by the institutional Bioethics Committee and all animal handling was performed according to established guidelines.

\section{MEXICANA INFECTION}

Three weeks after the second immunization dose, hamsters were infected in the left hind foot pad with 500 cultured L. mexicana metacyclic promastigotes (strain MNY/BZ/62/M379). Disease development was monitored for up to 17 weeks after infection by weekly measurement of footpad size with a vernier caliper, and lesion size was expressed as the difference in size between the infected and the contralateral uninfected footpad as described before (Saravia et al., 2005). Footpad swelling is indeed well correlated with parasite load during murine infection with L. mexicana (Aguilar
Torrentera et al., 2002), as well as in golden hamsters infected with L. brasiliensis or L. amazonensis (Sinagra et al., 2007). It is thus a reliable indicator of disease progression.

\section{RESULTS}

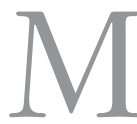
easurement of footpad lesion size showed that male golden hamsters were significantly more susceptible to L. mexicana infection than females, as their lesions grew larger and faster than females (Fig. 1). After 17 weeks of infection, control males presented lesion twice as large as control female hamsters. DNA vaccinated females developed significantly smaller lesions than vector or saline control females, indicating that they were significantly protected by the DNA vaccine (Fig. 1A). By the end of the experiment, vaccinate females hamsters presented a reduction in lesion size of $63 \%$ compared to control animals. On the other hand, vaccinated males presented lesions similar to non-vaccinated controls, suggesting that the vaccine had no effect (Fig. 1B). Also, there was a slight and transient exacerbation of the lesions in males immunized with the empty plasmid vector between weeks 4-11 weeks of infection, but this did not reach statistical significance.

\section{DISCUSSION}

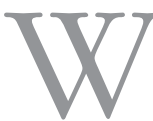
e evaluated here the efficacy of a DNA vaccine encoding NH36 and GP63 in a hamster model for the first time. The higher susceptibility of male golden hamsters to L. mexicana infec-
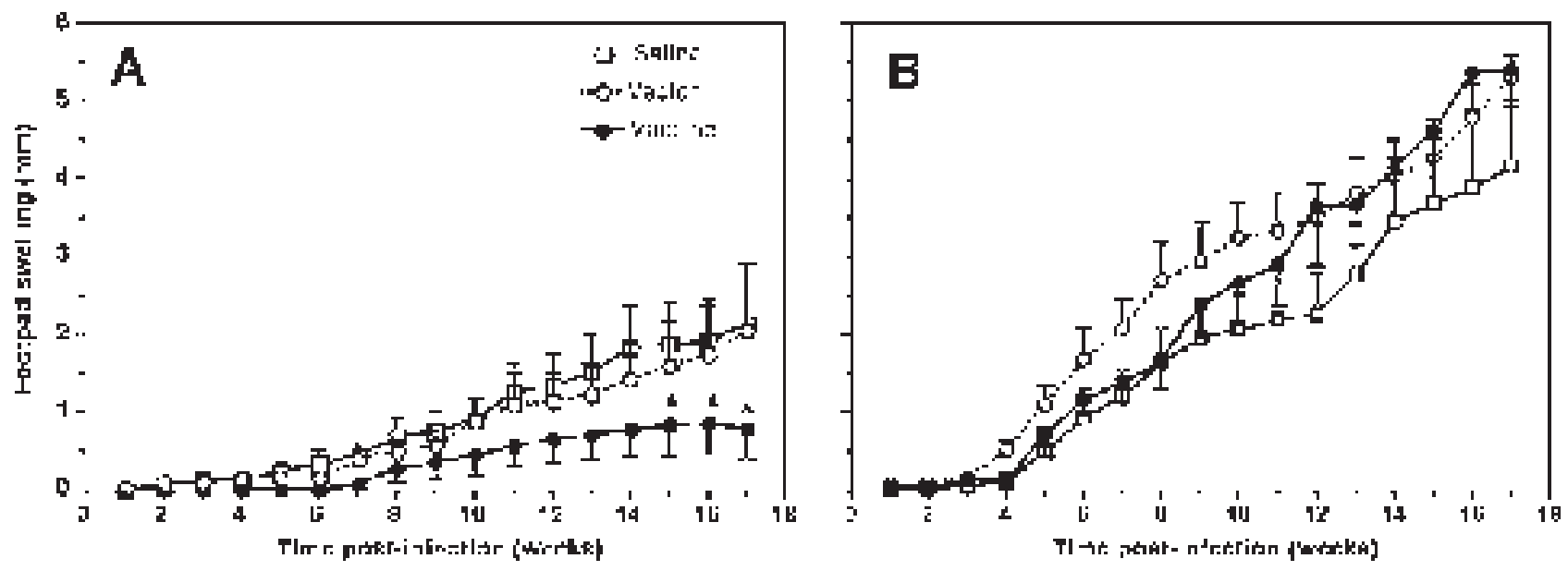

Fig. 1. - Lesion development in immunized hamsters infected with L. mexicana. Groups of 6-12 hamsters were immunized with a combination DNA vaccine encoding NH36 and GP63, the empty vector or saline solution. Following s.c. infection with 500 L. mexicana metacyclic promastigotes, lesion size was evaluated by weekly measurement of footpad thickness. Females (A) developed significantly smaller lesions than males (B). The DNA vaccine was able to significantly reduce lesion size in females (A) but not male hamsters (B). * indicates a significant difference with the saline control group (Tukey post-hoc test, $p<0.05$ ). 
tion is in agreement with a previous report (Saravia et al., 2005). Male DBA/2 mice have also been reported to be more susceptible to L. mexicana infection (Satoskar \& Alexander, 1995) and male hamsters to L. panamensis and L. guyanensis (Travi et al., 2002). In both mice and hamsters, this difference in susceptibility was attributed to differences in the pattern of Th1/Th2 cytokines expressed, with susceptible males having higher levels of IL-4, IL-10 and TGF- $\beta$ (Travi et al., 2002) or lower levels of IFN (Satoskar et al., 1998). Pregnancy (Osorio et al., 2008) and lactation (GomezOchoa et al., 2003) have both been found to reduce susceptibility to Leishmania infection in female hamsters. Gender differences in the incidence of visceral leishmaniasis has also been reported in human and dog populations, with males being usually more susceptible (Roberts et al., 2001; Snider et al., 2009). Sexual hormones are thought to contribute to the difference in cytokine production (Ahmadi \& McCruden, 2006; Lezama-Davila et al., 2007; Roberts et al., 2001; Travi et al., 2002). Indeed, gonadectomy and hormone therapy in mice suggest that estrogens are particularly associated with the ability of females but not males to produce IFN $\gamma$ and a Th1 immune response (Roberts et al., 2001). Sex-differences in susceptibility to infection have also been observed for other parasites such as Plasmodium (Klein et al., 2008; Snider et al., 2009). We further found that protection against L. mexicana was gender-specific, with female hamsters being significantly protected by the DNA vaccine, while males failed to show protection. Very variable protection has actually been obtained in the hamster model of $L$. mexicana infection. Indeed, a $p f r$-2 DNA vaccine provided transient protection in males hamsters, but exacerbated disease in females (Saravia et al., 2005). On the other hand, rPFR-2 protein immunization provided no significant protection in either male or female hamsters against $L$. mexicana, but induced protection in female hamsters against $L$. panamensis, while a prime-boost immunization with both $p f r$-2 DNA and protein induced protection against L. mexicana in females (Saravia et al., 2005). Taken together, these results are difficult to extrapolate to other species, including humans. A clinical trial of an autoclaved L. major vaccine plus BCG in iranian childrens (6-15 years old) resulted in a higher protection in boys compared to girls, but the reasons for this difference were unclear (Sharifi et al., 1998). Women are thought to have a greater ability to mount a Th1 immune response and would thus be expected to be more successfuly vaccinated (Snider et al., 2009). In any case, these data indicate that vaccination against Leishmania in humans is likely to be affected by gender and should be taken into account in vaccine trials and future vaccination campains.

Nonetheless, the $63 \%$ reduction in footpad lesion we observed in female hamsters is noteworthy, and this study expands the range of hosts in which the DNA vaccine encoding NH36 and GP63 can induce protection. It thus strengthens the use of this DNA vaccine approach, alone or in combination with additional antigens such as sand-fly salivary antigens (Gomes et al., 2008), for further evaluation in additional animal models.

\section{ACKNOWLEDGEMENTS} his work was funded by the Consejo Nacional
de Ciencia y Tecnologia (CONACYT), Mexico,
grant \#SEP-2004-C01-47122 to E.D.

\section{REFERENCES}

Aguilar Torrentera F., Lambot M.A., Laman J.D., Van Meurs M., Kiss R., Noel J. C. \& Carlier Y. Parasitic load and histopathology of cutaneous lesions, lymph node, spleen, and liver from BALB/C and C57BL/6 mice infected with Leishmania mexicana. American Journal of Tropical Medicine and Hygiene, 2002, 66 (3), 273-279.

Agullar-Be I., da Silva Zardo R., Paraguai de Souza E., BorjaCabrera G.P., Rosado-Vallado M., Mut-Martin M., GarciaMiss M.R., Palatnik de Sousa C.B. \& Dumonteil E. Crossprotective efficacy of a prophylactic Leishmania donovani DNA vaccine against visceral and cutaneous murine leishmaniasis. Infection E Immunity, 2005, 73 (2), 812-819.

Ahmadi K. \& McCRUden A.B. Macrophage may responses to androgen via its receptor. Medical Science Monitor, 2006, 12 (1), BR15-20.

Al-Wabel M.A., Tonui W. K., Cui L., Martin S. K. \& Titus R.G. Protection of susceptible BALB/c mice from challenge with Leishmania major by nucleoside hydrolase, a soluble exo-antigen of Leishmania. American Journal of Tropical Medicine and Hygiene, 2007, 77 (6), 1060-1065.

Andrade-Narvaez F.J., Simmonds-Diaz E., Rico-Aguilar S., Andrade-Narvaez M., Palomo-Cetina A., Canto-Lara S.B., Garcia-Miss M.R., Madera-Sevilla M. \& Albertos-Apulche N. Incidence of localized cutaneous leishmaniasis (chiclero's ulcer) in Mexico. Transactions of the Royal Society of Tropical Medicine and Hygiene, 1990, 84, 219-220.

Arruda M.S., Nogueira M.E. \& Bordon A.P. Histological evaluation of the lesion induced by inoculation of Leishmania mexicana in the cheek pouch of the hamster. Revista da Sociedade Brasileira de Medicina Tropica, 2002, 35 (4), 293-297.

DUMONTEIL E. DNA vaccines against protozoan parasites: opportunities and challenges. Journal of Biomedicine and Biotechnology, 2007, 2007, 90520.

Dumonteil E., McMahon-Pratt D. \& Price V. Report on the fourth TDR/IDRI meeting on second-generation vaccines against Leishmaniasis, 1-3 May 2001, Universidad Autonoma de Yucatan, Mexico. TDR/PDR/LEISH/VAC/011, 2001.

Gamboa-León R., Paraguai de Souza E., Borja-Cabrera G.P., Pinheiro O.R., Dumonteil E. \& Palatnik de Sousa C.B. 
Immunotherapy against murine visceral leishmaniasis with the nucleoside hydrolase DNA vaccine of Leishmania donovani. Vaccine, 2006, 24 (22), 4863-4873.

Garcia-Miss M.R., Andrade-Narvaez F.J., Esquivel-Vinas R.E., Simmonds-Diaz E. B., Canto-Lara S.B. \& Cruz-Ruiz A.L. Localized cutaneous leishmaniasis (chiclero's ulcer) in Mexico: sensitivity and specificity of ELISA for IgG antibodies to Leishmania mexicana mexicana. Transactions of the Royal Society of Tropical Medicine and Hygiene, 1990, 84, 356-358.

GARG R. \& DubE A. Animal models for vaccine studies for visceral leishmaniasis. Indian Journal of Medical Research, 2006, 123 (3), 439-454.

Gomes R., Teixeira C., Teixeira M.J., Oliveira F., Menezes M.J., Silva C., De Oliveira C.I., Miranda J.C., Elnaiem D.E., KamHaWI S., Valenzuela J.G. \& Brodskyn C.I. Immunity to a salivary protein of a sand fly vector protects against the fatal outcome of visceral leishmaniasis in a hamster model. Proceedings of the National Academy of Science of the USA, 2008, 105 (22), 7845-7850.

Gomez-Ochoa P., Gascon F. M., Lucientes J., Larraga V. \& CASTILLO J.A. Lactating females Syrian hamster (Mesocricetus auratus) show protection against experimental Leishmania infantum infection. Veterinary Parasitology, 2003, 116, (1), 61-64.

Klein P.W., Easterbrook J.D., Lalime E.N. \& Klein S.L. Estrogen and progesterone affect responses to malaria infection in female C57BL/6 mice. Gender Medecine, 2008, 5 (4), 423433.

Lezama-Davila C.M., IsaAc-Marquez A.P., Barbi J., Oghumu S. \& SATOSKAR A.R. 17Beta-estradiol increases Leishmania mexicana killing in macrophages from $\mathrm{DBA} / 2$ mice by enhancing production of nitric oxide but not pro-inflammatory cytokines. American Journal of Tropical Medicine and Hygiene, 2007, 76 (6), 1125-1127.

Melby P.C., Chandrasekar B., ZhaO W. \& Coe J.E. The hamster as a model of human visceral leishmaniasis: progressive disease and impaired generation of nitric oxide in the face of a prominent Th1-like cytokine response. Journal of Immunology, 2001, 166 (3), 1912-1920.

OliveIRA F.J. \& CECCHINI R. Oxidative stress of liver in hamsters infected with Leishmania (L.) chagasi. Journal of Parasitology, 2000, 86 (5), 1067-1072.

Osorio Y., Bonilla D.L., Peniche A.G., Melby P.C. \& Travi B.L. Pregnancy enhances the innate immune response in experimental cutaneous leishmaniasis through hormonemodulated nitric oxide production. Journal of Leukocyte Biology, 2008, 83 (6), 1413-1422.

PALATNIK-DE-Sousa C.B. Vaccines for leishmaniasis in the fore coming 25 years. Vaccine, 2008, 26 (14), 1709-1724.

Ramos-Santos C., Hernandez-Montes O., Sanchez-Tejeda G. \& Monroy-Ostria A. Visceral leishmaniosis caused by Leishmania (L.) mexicana in a Mexican patient with human immunodeficiency virus infection. Memorias do Instituto Oswaldo Cruz, 2000, 95 (5), 733-737.

Requena J.M., Soto M., Doria M.D. \& Alonso C. Immune and clinical parameters associated with Leishmania infantum infection in the golden hamster model. Veterinary Immunology and Immunopathology, 2000, 76 (3-4), 269-281.
Roberts C.W., WALKer W. \& AleXANDER J. Sex-associated hormones and immunity to protozoan parasites. Clinical Microbiology Review, 2001, 14 (3), 476-488.

Rosado-Vallado M., Mut-Martin M., Garcia-Miss M.R. \& DumonteIL E. Aluminium phosphate potentiates DNA vaccines against Leishmania mexicana. Vaccine, 2005, 23 (4647), 5372-5379.

Saravia N.G., Hazbon M.H., Osorio Y., Valderrama L., Walker J., Santrich C., Cortazar T., Lebowitz J.H. \& Travi B.L. Protective immunogenicity of the paraflagellar rod protein 2 of Leishmania mexicana. Vaccine, 2005, 23 (8), 984-995.

Satoskar A., Al-Quassi H.H. \& Alexander J. Sex-determined resistance against Leishmania mexicana is associated with the preferential induction of a Th1-like response and IFNgamma production by female but not male DBA/ 2 mice. Immunology and Cell Biology, 1998, 76, 159-166.

Satoskar A. \& Alexander J. Sex-determined susceptibility and differential IFN-gamma and TNF-alpha mRNA expression in DBA/2 mice infected with Leishmania mexicana. Immunology, 1995, 84, 1-4.

Sharifi I., FeKri A.R., Aflatonian M.R., Khamesipour A., Nadim A., Ahmadi-Mousavi M.R., Momeni A.Z., Dowlati Y., Godal T., ZicKer F. \& SMith P.G. Ramdomised vaccine trial of single dose of killed Leishmania major plus BCG against anthroponotic cutaneous leishmaniasis in Bam, Iran. Lancet, 1998, 351, 1540-1543.

Sinagra A., Luna C., Abraham D., Iannella Mdel C., Riarte A. \& KROLEWIECKI A.J. The activity of azithromycin against Leishmania (Viannia) braziliensis and Leishmania (Leishmania) amazonensis in the golden hamster model. Revista da Sociedade Brasileira de Medicina Tropical, 2007, 40, (6), 627-630.

Snider H., Lezama-Davila C., Alexander J. \& Satoskar A.R. Sex hormones and modulation of immunity against leishmaniasis. Neuroimmunomodulation, 2009, 16, (2), 106-113.

SOLIman M.F. The persistence, dissemination, and visceralization tendency of Leishmania major in Syrian hamsters. Acta Trop., 2006, 97 (2), 146-150.

Travi B.L., Osorio Y., Melby P.C., Chandrasekar B., Arteaga L. \& SARAVIA N.G. Gender is a major determinant of the clinical evolution and immune response in hamsters infected with Leishmania spp. Infection E Immunity, 2002, 70 (5), 2288-2296.

Velasco O., Savarino S.J., Walton B.C., Gam A. A. \& Neva F.A. Diffuse cutaneous leishmaniasis in Mexico. American Journal of Tropical Medicine and Hygiene, 1989, 41 (3), 280-288.

Reçu le 5 mai 2009

Accepté le 29 juin 2009 